\title{
O QUE SERIA A CONSCIÊNCIA NA FENOMENOLOGIA HEIDEGGERIANA?
}

\author{
Ronaldo Manzi ${ }^{1}$ \\ Universidade de São Paulo (USP)
}

\begin{abstract}
RESUMO:
é quase natural associarmos a fenomenologia a uma filosofia da consciência. A pretensão de Husserl de realizar um idealismo transcendental tendo o ego transcendental como o fundamento da razão não nos deixa muitas brechas para pensarmos diferente. O modo como Husserl foi lido na França também não nos ajuda a pensar de outro modo. Entretanto, seu aluno, Martin Heidegger, parece propor algo diferente. Sim, a consciência é uma questão fundamental do pensamento filosófico. Mas seria preciso reduzir a filosofia a uma questão sobre a consciência? Esse texto busca mostrar que não. Seria possível pensarmos a fenomenologia de um outro modo.
\end{abstract}

PALAVRAS-CHAVE: Fenomenologia; Ontologia; Consciência; Dasein; Existência.

\section{WHAT WOULD BE CONSCIOUSNESS IN HEIDEGGER'S PHENOMENOLOGY?}

\begin{abstract}
:
it is almost natural to associate phenomenology with philosophy of consciousness. Husserl's attempt to develop a transcendental idealism having the transcendental ego as the foundation of reason does not leave us many loopholes to think different. How Husserl was read in France does not help us to think otherwise. However, his student, Martin Heidegger, seems to propose something different. Yes, consciousness is a fundamental question of philosophical thought. But it would be necessary to reduce philosophy to a question about consciousness? This text seeks to answer no to that question. It would be possible to think phenomenology in another way.
\end{abstract}

KEYWORDS: Phenomenology; Ontology; Consciousness; Dasein; Existence.

1 Doutor em filosofia pela Universidade de São Paulo (USP), São Paulo - Brasil e pela Radboud Universiteit Nijmegen (RUN) (co-tutela) - Holanda. Pós-doutorando em filosofia pela Universidade de São Paulo (USP). Bolsista Fapesp. Contato: manzifilho@ hotmail.com 


\title{
O que seria a consciência na fenomenologia heideggeriana?
}

É quase natural associarmos a fenomenologia a uma filosofia da consciência. A pretensão de Husserl de realizar um idealismo transcendental tendo o ego transcendental como o fundamento da razão não nos deixa muitas brechas para pensarmos diferente. O modo como Husserl foi lido na França também não nos ajuda a pensar de outro modo. Entretanto, seu aluno, Martin Heidegger, parece propor algo diferente. Sim, a consciência é uma questão fundamental do pensamento filosófico. Mas seria preciso reduzir a filosofia a uma questão sobre a consciência? Esse texto busca mostrar que não. Seria possível pensarmos a fenomenologia de um outro modo.

\section{0 método fenomenológico segundo Heidegger}

Entre 1925-1926, Heidegger ministra um curso intitulado Lógica - A questão da verdade. Nos prolegômenos desse curso, Heidegger retoma as investigações de Husserl e define a fenomenologia assim:

\begin{abstract}
a principal coisa é o princípio que guia o trabalho, um que podemos denominar fenomenológico. Tomado como um todo, esse princípio não é nada novo mais é uma de várias saídas na filosofia que se passa sem ser dita. O princípio é que nós podemos investigar e desenvolver os objetos da filosofia justamente no modo em que eles aparecem. Assim, a tendência a pesar as questões reais em si mesmas, para liberá-las de pressuposições, cobertas pela tradição, e questões impensadas sobrecarregadas de pressuposições. Essa é a confiança própria da fenomenologia: ir para as questões reais elas mesmas. Um simples 'fenômeno' significa um objeto dado de investigação filosófica tal como ele é apreendido com a intenção de compreendê-lo tal como ele é. Então, num certo sentido, a palavra 'fenômeno' sempre implica uma tarefa: negativamente, uma proteção contra pressuposições e prejulgamentos; positivamente, assegurar que a análise do chamado fenômeno deve ficar claro consigo sobre quais pressuposições ele traz aos objetos da filosofia. Por último, podemos mostrar que ninguém pode seguir sem tal pressuposição e, por isso, que a crítica do ato essencial de pressupor é um elemento essencial da pesquisa filosófica (HEIDEGGER, 2010, p. 28).
\end{abstract}

Estas são linhas concordantes com o "espírito" fenomenológico husserliano. Aparentemente, Heidegger é um fenomenólogo aos moldes do pensamento de seu professor. Entretanto, a experiência de pensamento de Heidegger é marcadamente ontológica. Desde a primeira linha de Ser $e$ tempo de 1927, Heidegger afirma que "essa pergunta [pelo sentido do ser] está hoje esquecida, apesar de nossa época ter na conta de um progresso a 
reafirmação da 'metafísica'" (HEIDEGGER, 2012b, p. 33). Ou seja, Heidegger deixa claro como a pergunta sobre o sentido do ser é a questão central na filosofia e que, mesmo assim, ela foi abandonada na sua história.

Para retomar essa questão central, Heidegger não só compreende a fenomenologia de um modo diferente como também a distorce. A fenomenologia, aos seus olhos, tem um compromisso ontológico e por isso aparece em sua obra enquanto uma questão de método de analisar as teses sobre o ser. Isto é, ela seria um método que se dirige para o ser, pois, mesmo que as coisas se deixem e se façam ver por si mesmas, algo permanece velado, encoberto e esquecido:

a fenomenologia é o modo-de-acesso ao que deve se tornar da ontologia por determinação demonstrativa. A ontologia só é possível como fenomenologia. O conceito fenomenológico de fenômeno designa, como o que se mostra, o ser do ente, seu sentido, suas modificações e derivados, e o mostrar-se não é um mostrar-se qualquer, nem também algo assim como o aparecer. O ser do ente é o que menos pode ser concebido como algo 'atrás' do qual ainda haveria algo que 'não aparece' (HEIDEGGER, 2012b, p. 123).

Trata-se de uma forma de pensar que se desvia da fenomenologia husserliana, como Heidegger mesmo afirma nesta outra passagem (de um curso ministrado na época em que escrevia Ser e tempo - no semestre de verão de 1927) explicitando o que ele compreende por redução fenomenológica:

para Husserl, a redução fenomenológica, que foi trabalhada pela primeira vez expressamente nas Ideias para uma fenomenologia pura e para uma filosofia fenomenológica (1913), é o método de recondução do olhar fenomenológico da atitude natural do homem que vive imerso no mundo das coisas e das pessoas para a vida transcendental da consciência e suas vivências noético-noemáticas, vivências nas quais os objetos se constituem como correlatos de consciência. Para nós, a redução fenomenológica significa a recondução do olhar fenomenológico da apreensão do ente, como quer que uma tal apreensão se determine, para a compreensão do ser desse ente (projetada com vistas ao modo de seu desvelamento (HEIDEGGER, 2012a, pp. 36-37).

Isso nos diz algo: a própria necessidade de redefinir o que é a fenomenologia e a redução fenomenológica mostra que Heidegger reconhece a importância deste movimento e, ao mesmo tempo, exige que algo deve ser repensado.

Seu ponto de partida é a questão sobre o sentido do ser do ente uma questão ontológica por excelência. E como afirma Hans-Georg 
Gadamer, trata-se de um novo caminho em direção à metafísica (cf. GADAMER, 2012, p. 177).

Para empreender esse novo caminho, Heidegger se volta a um método que ele considera próprio ao tratamento das coisas elas mesmas. Este método é a fenomenologia. Assim ele se exprime:

com a pergunta diretora pelo sentido do ser, a investigação se põe ante a pergunta fundamental da filosofia em geral. $\mathrm{O}$ modo-de-tratamento dessa pergunta é o fenomenológico. Isso não prescreve ao presente tratado nem um 'ponto-de-vista', nem a subordinação a uma 'corrente', pois a fenomenologia não é nenhuma dessas coisas e jamais poderá sê-lo, enquanto tiver o entendimento de si mesma. A expressão 'fenomenologia' tem a significação primária de um conceitode-método (HEIDEGGER, 2012b, p. 101).

Para explicar o que é a fenomenologia, a estratégia de Heidegger é analisar os dois termos que compõem o conceito: fenômeno e logos. O que é o fenômeno? O que é o logos? E o que é esta suposta ciência dos fenômenos?

Fenômeno é uma palavra grega que tem dois sentidos segundo Heidegger: significa que algo se mostra, se torna manifesto, visível em si mesmo, o-que-se-mostra-em-si-mesmo: "fenômeno - o mostrar-se-em-simesmo - significa um modo assinalado de algo vir-de-encontro" (HEIDEGGER, 2012b, p. 109).

Logos, por sua vez, significa um tornar manifesto aquilo que se discorre no discurso. Nesse sentido, o logos faz com que vejamos algo: aquilo sobre a qual se discorre - tal como um dito, pois “(...) o dito no discurso deve ser extraído daquilo sobre o que se discorre, de tal maneira que a comunicação por discurso torne manifesto no dito e, assim, acessível ao outro aquilo sobre o que se discorre" (HEIDEGGER, 2012b, p. 115). O dito seria, portanto, um certo discorrer em palavras que se faz ver, se faz manifesto. Falar faz ver, perceber o que se se manifesta.

Oswaldo Giacoia Junior destaca esta concepção do logos ao se perguntar o que quer dizer uma análise fenomenológica em Heidegger. Ele diz:

a palavra 'análise' se refere à decomposição do ser-o-aí [Dasein] em suas estruturas ontológicas, que ele denomina existenciais-ontológicas, para diferenciar de todo predicado ôntico, referido unicamente aos entes. Análise fenomenológica, no sentido originário tanto de phainomenon quanto de logos, que, como o traduz Heidegger, é fundamentalmente verbo, discurso. Para ele, todas as outras significações do termo, como lógica, juízo, verdade, razão, fundamento, relação, são derivadas da acepção originária de fala (em alemão, Rede). Ligado ao verbo legein, logos é a palavra ou a enunciação que 
reúne e mostra, no sentido de fazer ver, aquilo de que fala o discurso (GIACOIA, 2013, p. 68).

Desse modo, a fenomenologia é aquilo que se faz ver a partir da coisa mesma. Isto é sinônimo da concepção de voltar às coisas elas mesmas. Por isso, ao realizar uma "ciência 'de' os fenômenos", afirma Heidegger, "significa: uma apreensão de seus objetos de tal maneira que tudo o que esteja em discussão a seu respeito deve ser tratado numa mostração direta e numa demonstração direta" (HEIDEGGER, 2012b, § 7c) - a cientificidade da fenomenologia está na sua capacidade de determinar o modo de vir ao encontro próprio dos fenômenos.

Ainda é necessário determinar de modo preciso o que o fenômeno nos faz ver. Segundo Heidegger, o que se mostra não é o mais óbvio, é algo que permanece oculto, que fica muitas vezes esquecido: o ser do ente. Ocultar-se não significa que há algo "atrás" do fenômeno, e sim oculto no próprio fenômeno: sua essência. Por isso afirma:

\begin{abstract}
a fenomenologia é o modo-de-acesso ao que deve se tornar tema da ontologia por determinação demonstrativa. O conceito fenomenológico de fenômeno designa, como o que se mostra, o ser do ente, seu sentido, suas modificações e derivados. E o mostrar-se não é um mostrar-se qualquer, nem também algo assim como o aparecer. O ser do ente é o que menos pode ser concebido como algo 'atrás' do qual ainda haveria algo que 'não aparece' (HEIDEGGER, 2012b, § 7c).
\end{abstract}

Algo está encoberto porque ainda não foi descoberto ou pode ter sido novamente encoberto. A fenomenologia é o método que torna possível descobrir a essência de algo ou o seu sentido oculto. Por isto, para saber se se está lidando com algo encoberto ou um mero "disfarce" do que seria a essência, a fenomenologia deve ser crítica de si. É no próprio fenômeno que se deve buscar saber se se está descrevendo sua essência ou não.

A fenomenologia é o método que torna possível descobrir a essência de algo (o seu sentido oculto). Para saber se se está lidando com algo encoberto ou um mero "disfarce" do que seria a essência, a fenomenologia deve ser crítica de si: é no próprio fenômeno que se deve buscar saber se se está descrevendo sua essência ou não.

Enquanto demonstração, a fenomenologia deve ser uma hermenêutica, tendo como meta interpretar ontologicamente o ser do ente:

ontologia e fenomenologia não são duas disciplinas diversas que, ao lado de outras, pertencem à filosofia. Ambos os termos caracterizam a filosofia ela mesma, segundo o objeto e segundo o modo-de-tratamento. Filosofia é ontologia fenomenológica universal cujo ponto de partida é a hermenêutica do Dasein, a qual, como analítica da existência, fixou a ponta do fio- 
condutor de todo perguntar filosófico lá de onde ele surge e para onde ele retorna (HEIDEGGER, 2012b, p. 129).

Enquanto método, a fenomenologia tem três componentes fundamentais segundo Heidegger: redução, construção e destruição. A redução fenomenológica é compreendida como um direcionar: toda investigação ontológica só é acessível por um ente privilegiado: o Dasein. Mas mesmo se encaminhando a um ente, a investigação é conduzida para além dele. Ela se volta para o seu ser: uma recondução do olhar do ente para o ser.

Em segundo lugar, a fenomenologia é uma construção. Isto é, ela é uma certa projeção do Dasein em vista do seu ser e às suas estruturas. Por isso, a consideração do ser tem como ponto de partida o ente. Isto significa que tanto a essência quanto à existência (desse ente em especial, o Dasein) estão em questão. Giacoia Junior destaca isto nessa passagem:

se a ontologia geral concede privilégio teórico à essência em relação à existência, Heidegger, ao contrário, pensa o Dasein como ente cuja ex-sistência é ontologicamente fundamental, ou seja, é constitutiva da essência: uma existência contingente, temporal, mundana, finita, cujo sentido é ser-para-a-morte (GIACOIA, 2013, p. 63).

Sendo assim, toda construção se dá historicamente, porque é próprio deste ente sua historicidade: "como o ser-aí [Dasein] é histórico em sua própria existência, as possibilidades de acesso e os modos de interpretação dos entes são eles mesmos diversos, variando em conjunturas históricas diferentes" (HEIDEGGER, 2012b, § 5).

Por fim, sendo o Dasein um ente histórico, cabe a ele uma destruição ou uma "desconstrução" (como gostam os franceses de traduzir essa ideia) crítica dos conceitos da história da filosofia que precisam ser desencobertos. É preciso, portanto, uma forma de desnaturalização de nossas formas de pensar: "a construção da filosofia é necessariamente destruição, isto é, uma desconstrução daquilo que foi legado realizada em meio a um retrocesso historiográfico à tradição" (HEIDEGGER, 2012b, § 5). É somente a partir da história da filosofia que se constrói algo novo que se descobre o que estava velado ou mesmo impensado.

Assim, quando pensamos a fenomenologia enquanto filosofia da consciência, não parece correto termos em mente Heidegger. Apesar de a dedicatória de Ser e tempo ser "a Edmund Husserl em testemunho de admiração e amizade", Heidegger não é husserliano. A concepção de Heidegger se distancia largamente da experiência intelectual de Husserl ao insistir nos modos-de-ser do Dasein (ser-aí em que está em jogo o ser do seu "aí") na tentativa de desvelar o sentido do ser em geral.

Contudo, não é verdade que Heidegger simplesmente ignora a questão da consciência. O que ele faz é tomá-la de outra forma, enquanto 
um fenômeno do Dasein que remonta à constituição ontológica desse ente. Vale nos voltarmos a algumas páginas sobre esse tema para justificarmos melhor o porquê de Heidegger não ser tomado aqui enquanto um filósofo da consciência, mesmo tendo desenvolvido a questão da consciência em seu Ser e tempo.

\section{Ser-para-a-morte}

No segundo capítulo da segunda seção (Dasein e temporalidade) de Ser e tempo denominado A atestação conforme ao Dasein de um poder-ser próprio $e$ o ser-resoluto, Heidegger se debruça sobre a questão da consciência. Esse capítulo se segue ao primeiro que se denomina $O$ possível ser-um-todo do Dasein e o ser-para-a-morte. Não por acaso. É preciso deixar claro como a consciência aparece na reflexão heideggeriana enquanto um poder-ser que está intimamente ligado à constituição ontológica do Dasein, sendo que esse ente é um ser-para-a-morte.

Heidegger define o que é a consciência. Tentemos compreender o que estas palavras dizem: "a consciência é o apelo da preocupação a partir do estranhamento do ser-no-mundo que desperta o Dasein para o seu poderser-culpado mais próprio" (HEIDEGGER, 2012b, p. 791).

No parágrafo 40 de Ser e Tempo, Heidegger descreve $O$ encontrarse-fundamental da angústia como uma assinalada abertura do Dasein. Neste parágrafo, Heidegger irá mostrar como há uma estranheza do Dasein decidir ser si mesmo. Uma estranheza que leva o Dasein a se sufocar com algo indeterminado, próximo e não apontável, que lhe sufoca a respiração e que lhe é o mais familiar. Decidido a não mais se ocupar com as coisas cotidianas e se voltando ao que lhe é mais próprio, o Dasein se ocupa da estranheza, literalmente, de ser-aí. Isso parece ser sentido como angústia. Como entendê-la?

Comecemos lembrando como no parágrafo 9 , denominado $O$ tema da analítica do Dasein, Heidegger descreve a essência desse ser-aí. Segundo suas palavras, o Dasein é um ente que está entregue à responsabilidade de assumir seu próprio ser: cabe a ele decidir esta assunção ou não. O que está em jogo aqui, para Heidegger, é o próprio ser. A essência do Dasein é uma espécie de jogo de decisão em que sua própria existência está em "aposta". Assim, existir é uma determinação ontológica do Dasein. Heidegger quer com isto afirmar que este ser, que está aí, lançado no mundo, só está presente a si mesmo enquanto um possessivo. O que está em jogo é sempre o meu ser e não uma coisa entre outras (meu ser, aquilo que sou, não é um tema entre outros, mas a determinação mais própria de minha existência).

Entretanto, o Dasein nem sempre está ocupado consigo. Ele pode muito bem estar mergulhado na vida cotidiana sem se colocar em questão. Melhor, sem se compreender. Heidegger descreve esta compreensão num 
capítulo denominado $O$ ser-em como tal. Seu objetivo geral é realizar uma explicitação da tarefa de interpretar o modo de ser do Dasein na cotidianidade do aí.

A primeira coisa que devemos ter em mente é que este ser, esse Dasein, é um ser em relação. Ele é um ser-em, segundo a notação heideggeriana; é também um ser junto a algo. Ou seja, o Dasein é um ser preocupado - que se preocupa com os outros ao seu redor; e é um ser ocupado - que se ocupa das coisas circundantes. Tanto a preocupação quanto a ocupação do Dasein, obviamente, lhe dizem respeito. Estão presentes em toda atitude e situação de fato - o Dasein está absorvido naquilo com a qual se relaciona. Para que esse Dasein tenha qualquer tipo de relação, consequentemente, ele está aberto ao mundo: está em relação ao mundo, junto a ele. Afinal, ele é, literalmente, um ser-no-mundo, um ser que existe presentemente enquanto abertura. Uma abertura que possibilita o que este ente está sendo, foi e será. Ele é um ser de possibilidades.

Heidegger propõe pensarmos então a constituição existencial do aí do Dasein (é daqui que iremos nos voltar ao tema da consciência). O que são estas possibilidades? Qual é a constituição existencial do ser-aí? Estes são parágrafos centrais para compreendermos a finitude, a eleição e a existência.

No parágrafo em que Heidegger denomina $O$ ser do Dasein como preocupação, ele tem como tema delimitar a estrutura da preocupação/disposição enquanto modo originário de abertura do Dasein em seu estar-lançado/dejetado. Ou seja, o Dasein sempre já está no mundo, já está lançado aí. Enquanto aberto ao mundo, ele tem uma disposição a ele. Esta disposição é descrita por Heidegger enquanto um existencial fundamental em que o Dasein está sempre num estado de humor e sempre sendo responsável por ele.

Sem dúvida alguma, enquanto um ser-no-mundo, o Dasein não pode deixar de estar entregue a um estado em que ele mesmo é responsável. Do mesmo modo, o Dasein pode estar cego a si mesmo e entregue a um estado de ocupação sem ter em conta seu mau-humor. Isto significa que sua disposição fundamental com o mundo está ocupada, por sentir-se, possivelmente, ameaçado pelo mundo ao seu redor. Daí Heidegger dedicar um parágrafo a $O$ medo como um modus do encontrar-se, sendo este medo/temor uma possibilidade existencial da disposição essencial deste ente. Logo após esta descrição, Heidegger apresenta o que viria a ser uma chave de leitura de $O$ ser e o tempo: $O$ "ser-aí" como entender. Trata-se de descrever o entender (a compreensão) enquanto um existencial fundamental da existência. O que isto significa?

Heidegger descreve a compreensão enquanto uma abertura em que subsiste algo que pode-ser. Nesta abertura, todo Dasein, pode vir a ser algo: um projeto. Isto é o fundamental: enquanto projeto, todo Dasein toma uma decisão em se lançar no futuro - o Dasein projeta um destino e se dispõe a 
ele. É este ponto que Gadamer tem em vista ao afirmar que "Heidegger, que foi o primeiro a cunhar o conceito de compreensão como uma determinação universal do ser-aí, tem em mente com isso, exatamente, o caráter de projeto da compreensão; isto significa, porém, o caráter de futuro do ser-aí [Dasein]" (GADAMER, 1997, p. 27).

Claro que todo Dasein já se lançou ao mundo de algum modo e por isto já se compreendeu: todo Dasein já tem uma estória de decisões e se encontra aberto a novas possibilidades de se lançar a algo diferente: está em suas mãos eleger seu destino. Neste sentido, o Dasein é sempre mais do que é (sempre algo aberto ao possível).

Isto faz com que Heidegger afirme que, partindo da ontologia, esta abertura, essa possibilidade, esta compreensão, é a determinação mais originária e mais positiva do Dasein, porque é só a partir dela que o Dasein pode ser do modo mais próprio.

No parágrafo seguinte, Heidegger tem como tema outro ponto central: Entender e interpretação. Ou seja, a todo o momento que o Dasein projeta o entender (a compreensão) ele possui possibilidades de elaborálo(a). Este ato de elaboração é uma interpretação. Mas como a interpretação depende da compreensão, esta última continua sendo o existencial fundamental: só se interpreta para que a compreensão se compreenda, para que haja uma apropriação do que se compreende. O que isto significa?

Para Heidegger, só compreendemos algo porque já tínhamos uma compreensão prévia do que se trata - temos sempre uma posição prévia de algo. Ao compreender algo, a partir desta posição prévia, realizamos uma espécie de retirada do estranhamento, porque tínhamos uma visão previdente do que este algo seria. Há, portanto, uma decisão na compreensão baseada no que prevemos e no que nos apoiamos previamente - modo de dizer que sempre há uma pressuposição.

Interpretar seria entrar numa espécie de círculo: para se compreender algo, é impossível não termos uma posição prévia. Heidegger afirma que o decisivo não é sair do círculo, mas entrar no círculo de modo adequado. E, logo à frente, complementa:

\footnotetext{
nele [no círculo] se abriga uma possibilidade positiva de conhecimento o mais originário, possibilidade que só pode ser verdadeiramente efetivada de modo autêntico, se a interpretação entende que sua primeira, constante e última tarefa consiste em não deixar que o ter-prévio e o conceberprévio lhe sejam dados por ocorrências e conceitos populares, mas em se assegurar do tema científico mediante sua elaboração a partir das coisas elas mesmas (HEIDEGGER, 2012b, p. 433).
}

Como se vê, esta posição, visão e concepção prévia são fundamentais para qualquer interpretação - a qualquer forma de decisão, porque só há decisões a partir do que se compreende. Compreender é o ser 
do poder-ser. O Dasein, enquanto aberto ao mundo, sempre já se compreendeu (porque já está lançado ao mundo). Ele sempre escolheu e assumiu a responsabilidade de suas escolhas (as possibilidades lhe foram lançadas).

Entretanto, ser livre para poder-ser mais próprio não significa, necessariamente, que o Dasein sempre se decide no que lhe é mais próprio. Ele é livre para isto, mas não determinado a tal. Lançado ao mundo, o Dasein tem duas possibilidades. Ele pode projetar a si enquanto o que lhe é mais próprio ou ele pode ser de modo impróprio. Ele pode viver na decadência, mergulhado no falatório, na curiosidade e/ou na ambiguidade. Ou seja, o Dasein pode se perder no meio público impessoal, não havendo nada de próprio em seu modo de ser (lembrando que o que está em jogo no ser do Dasein é sempre seu ser e não um ser impessoal/a-gente).

Para Heidegger, esta decadência, esta escolha de viver no impessoal, participa de um falatório, porque o Dasein passa a repetir e a passar adiante uma fala, não havendo, no fundo, nenhuma compreensão. Heidegger antecipa algo que será central na psicanálise: há falas originárias e falas passageiras, pois falar e dizer são atos distintos. Posso falar muito sem dizer nada; posso ficar em silêncio e dizer muito. $\mathrm{O}$ falar sem nada dizer seria o falatório.

Outro modo impróprio de ser é a curiosidade, pois o Dasein, neste caso, se ocupa no ver, sem compreender o que se vê. Ele age como se buscasse apenas o novo, sem apreender o que vê. Ele literalmente se abandona ao mundo. Por fim, Heidegger diz da ambiguidade: de um agir em que se passa como se tudo tivesse sido compreendido e discutido autenticamente, tendo um pressentimento em comum com os outros, mas sem nenhum compromisso. $\mathrm{O}$ falatório, a curiosidade e a ambiguidade são modos de ser impróprios do ser, que se ocupa e se preocupa com algo que não lhe é próprio, mas modos decadentes do Dasein.

De qualquer modo, o Dasein já está lançado ao mundo (ele sempre fez uma escolha - elegeu seu destino; ele já se empenhou em algo, mesmo que decadente). Mergulhado na decadência, o Dasein está tranquilizado e aprisionado - uma possibilidade do Dasein ser-aí. Uma possibilidade imprópria que encobre o que lhe é mais próprio. Entretanto, enquanto um ser lançado/dejectado no mundo, o Dasein pode ser algo que ainda não é (há algo pendente que o Dasein pode-ser). Diante disto, Heidegger nos diz sobre a finitude do Dasein, pois o que está sempre pendente é o fim: a morte.

Heidegger não só descreve o Dasein enquanto um ser-em relação com outros (preocupação); um ser-com outrem; um ser-junto-ao mundo; mas ele diz também de ser-para: com um fim, a saber, um ser-para-a-morte. No fundo, o existencial do modo de ser do Dasein por excelência.

Aqui começamos a compreender a angústia - uma angústia de algo familiar, um destino, que não podemos lutar contra. O que podemos fazer é 
assumir a finitude ou ignorá-la, encobri-la - agir de modo impessoal com o que nos é mais próprio.

A morte, assumida ou não, é um fenômeno da vida, um porvir que determina a existência, uma possibilidade privilegiada do Dasein. Privilegiada porque é o destino de toda existência ou, se se quer, uma possibilidade ontológica do Dasein, pois o que está em jogo é seu próprio ser. Trata-se de um porvir inevitável, uma possibilidade que, encobrindo ou não, fugindo ou não, acontecerá. Por isto, uma possibilidade privilegiada. Esta passagem é clara:

como poder-ser o Dasein não pode superar a possibilidade da morte. A morte é a possibilidade da pura e simples impossibilidade-de-ser-'aí'. Assim, a morte se desvenda como a possibilidade mais-própria, irremetente e insuperável. Como tal, a morte é um assinalado iminente, cuja possibilidade existenciária tem seu fundamento em que o Dasein é ele mesmo essencialmente aberto para ele mesmo e o é no modo do ser-adiantado-em-relação-a-si (HEIDEGGER, 2012b, p. 691).

Mas o fato de a morte ser a possibilidade mais própria, irremissível e insuperável, não significa que ela está assumida no horizonte do Dasein. Como dissemos, o Dasein é um poder-ser. Está em suas mãos assumir o que lhe é mais próprio ou não - eleger aquilo que se é ou que pode vir a ser.

Saber que se morre não significa assumir ser-para-a-morte. Ser-paraa-morte não significa tão quanto que se abandona à morte, mas que o Dasein assume o que lhe é mais próprio, mais familiar e, por isto, o mais angustiante. Diante desta angústia, podemos escolher que "sabe-se que se morre" - uma forma impessoal de lidar com nosso destino. Uma forma ambígua, que está no falatório do dia-a-dia. "Sei que as pessoas morrem e que, provavelmente, irei morrer" - este tipo de afirmação, para Heidegger, é uma forma de encobrir a possibilidade mais própria do Dasein; uma espécie de encobrimento da verdade em que se busca escapar da finitude.

Heidegger denomina esta fuga de ser-para-a-morte impróprio. E, ao contrário, a decisão de se aproximar do que se é mais familiar, próprio. Enquanto ser-lançado ao mundo, o Dasein está entregue à responsabilidade de sua morte.

Acredito que o parágrafo 53 de Ser e Tempo seja o parágrafo central sobre a finitude. Heidegger o intitula $O$ projeto existenciário de um serpara-a-morte próprio.

Lembremos que enquanto ser aberto ao mundo, o Dasein é um ser de compreensão e disposição. Sabemos que o que lhe é mais próprio nesta abertura é o poder-ser próprio e inescapável que é ser-para-a-morte. Trata-se de algo que não se pode escapar, pois a existência se define em sua finitude. É neste sentido que Heidegger afirma que, "o quem do Dasein no mais das vezes não sou eu mesmo, mas a-gente-ela-mesma [próprio-impessoal]" 
(HEIDEGGER, 2012b, p. 735). Assim, o Dasein age de modo impessoal e não sabemos exatamente quem decidiu por isto ou aquilo... pois o Dasein está mergulhado no impessoal. Perdendo-se no impessoal, o Dasein se decide sobre o poder-ser mais imediato e factual. Sem projeção, tarefas, regras, parâmetros, a premência e a envergadura do ser-no-mundo da ocupação e preocupação são entregues a um quem que não sabemos ao certo quem é. É como se o Dasein não desse ouvido a si mesmo no que lhe é mais próprio.

Entretanto, o decidir-se a viver na angústia do que lhe é mais familiar é uma eleição singular de cada Dasein - uma recuperação da escolha de poder ser si mesmo. É verdade que o Dasein pode se decidir a adulterar, fingir, escapar, fugir desta angústia e viver de modo impróprio, sem ter seu ser em jogo. Daí, poderíamos nos questionar: do que adianta eu saber que vou morrer? Devo fazer uma perspectiva deste destino? Devo elegê-lo? Esperá-lo? Antecipá-lo? Realizá-lo? O que seria projetar-se para essa possibilidade?

Muito distante de afirmar que a assunção do ser-para-a-morte nos leva a realizá-la, de fato, Heidegger tem em mente um viver de modo próprio, sem enganar a existência de qualquer onipotência do pensamento. É preciso viver de modo autêntico com os outros, junto às coisas e ser-para.

É importante notar como Heidegger não quer fazer do projetar uma fixação. Nunca é bastante insistirmos que a ideia de uma fixação, no século $\mathrm{XX}$, sempre foi associada a um certo tipo de impedimento de realização das potencialidades do homem. Em estudos tão distantes quanto de Georges Canguilhem e Sigmund Freud, por exemplo, a fixação sempre esteve associada a uma patologia - a uma incapacidade de se impor qualquer tipo de normatividade ao mundo. Algo próximo encontramos em Heidegger neste momento: assumir que a possibilidade mais própria do Dasein é serpara-a-morte, não significa se fixar neste destino, mas uma forma de assumir o que se é no porvir. Entendemos, assim, passagens como esta de Heidegger: "resta considerar que o entender não significa primariamente ficar a contemplar embasbacado um sentido, mas entender-se no poder-ser que se desvenda no projeto" (HEIDEGGER, 2012b, p. 723).

Há uma passagem numa carta de Rainer Maria Rilke datada de 12 de agosto de 1904, que parece exemplificar, de modo concreto, o que Heidegger tinha em mente ao falar da fuga do ser-aí na cotidianidade. Tratase de uma carta das célebres Cartas a um jovem poeta de Rilke. Assim ele escreve sobre a morte:

as experiências a que se dá o nome de 'aparecimento', todo o pretenso mundo 'sobre-natural', a morte, todas estas coisas tão próximas de nós têm sido tão excluídas da vida, por uma defensiva cotidiana, que os sentidos com os quais as poderíamos aferrar se atrofiam. Nem falo em Deus. Mas a ânsia em face do inesclarecível não empobreceu apenas a 
existência do indivíduo, como também as relações de homem para homem, que, por assim dizer, foram retiradas do leito de um rio de possibilidades infindas para ficarem num ermo lugar da praia dos acontecimentos. Não é apenas a preguiça que faz as relações humanas se repetirem numa tão indizível monotonia em cada caso; é também o medo de algum acontecimento novo, incalculável, diante do qual não nos sentimos bastante fortes. Somente quem está preparado para tudo, quem não exclui nada, nem mesmo o mais enigmático, poderá viver sua relação com outrem como algo vivo e ir até o fundo de sua própria existência (RILKE, 2003, pp. 68-69).

O que Rilke parece sugerir é que o não enfrentamento da morte é uma atrofia, uma fixação num mesmo que impede aquilo que Heidegger define um poder-ser. A monotonia parece advir de um temor do que nos é familiar ou, como diz, Heidegger, de algo singular:

\begin{abstract}
a possibilidade mais-própria é não-relativa. O adiantar-se faz que o Dasein entenda que deve assumir unicamente a partir de si mesmo o poder-ser em que seu ser mais-próprio está pura e simplesmente em jogo. A morte não 'pertence' só indiferentemente ao Dasein próprio, mas ela o interpela como singular (HEIDEGGER, 2012b, p. 723).
\end{abstract}

É como se Heidegger tivesse defendendo que o ser-aí deve se angustiar frente ao que lhe é inevitável para enfrentar, ir de encontro, à sua singularidade.

É a partir dessa discussão que Heidegger introduz a questão sobre a consciência. Como se algo intimasse o Dasein a ir em direção a si mesmo. Heidegger introduz a consciência como uma voz que intima. É uma voz e um silêncio.

\title{
A consciência na ontologia heideggeriana
}

A consciência é apresentada em o Ser e tempo enquanto um fenômeno do Dasein que remonta à constituição ontológica desse ente. É aquilo que o intima ao seu ser mais próprio e, ao mesmo, tempo, aquilo que o repreende e o adverte.

Cada um pode ser aquilo que pode-ser, e pode o ser de forma própria ou imprópria. Trata-se de uma escolha. Na verdade, de uma escolha de uma escolha, uma vez que o Dasein, mesmo que não tenha escolhido isto ou aquilo, já se escolheu em algo. Mas o fato de realizar uma escolha, parece ser um passo único para se poder-ser mais próprio: "no escolher a escolha, o Dasein se possibilita pela primeira vez o seu poder-ser próprio" (HEIDEGGER, 2012b, p. 737).

Heidegger apresenta essa possibilidade enquanto um chamado, uma intimação, um apelo, uma voz que convoca e não nos diz nada: “(...) o apelo 
nada 'diz' que seja para discorrer, pois não dá conhecimento algum sobre acontecimentos" (HEIDEGGER, 2012b, p. 769).

Não se trata exatamente de uma voz tal como encontramos na filosofia prática kantiana. A consciência enquanto culpabilidade - é essa voz que não para de ressoar. Isto foi interpretado como uma teoria da consciência - algo que perde os fundamentos ontológicos do Dasein: "a caracterização da consciência como apelo não é, de modo algum, somente uma 'imagem', algo assim como a kantiana representação-do-tribunal da consciência. Não devemos, porém, omitir do discurso, e assim também do apelo, sua proferição verbal, como se fosse algo inessencial. Todo expressar e 'apelar' já pressupõem o discurso" (HEIDEGGER, 2012b, p. 745).

Poder-ser mais próprio - um apelo de si a si. Se algo diz, apela por isto, esse mesmo algo pode ou não ouvir este apelo. Isso é uma escolha: ouvir ou não?

Ouvir ou não o apelo da consciência é um determinado modo-de-ser do Dasein. Ouvir seria querer-ter-consciência - uma espécie de desejo de. Não ouvir a si, é entrar num falatório que emudece o apelo, pois "algo" apela e, não obstante, não dá nada a ouvir ao ouvido ocupado e curioso que possa ser passado adiante e ser discutido publicamente" (HEIDEGGER, 2012b, p. 761). A descrição desta possibilidade seria uma descrição dos fundamentos ontológico-existenciários da consciência enquanto abertura do aí (da disposição) do Dasein.

A distância aqui de Heidegger a Husserl é grande. O Dasein é, em sua estrutura ontológica, um ser-com, um ser-junto-a. Obviamente que encontramos um "papel" para a consciência em Heidegger, mas o fato dela figurar em sua ontologia não nos dá o "direito" de sugerir que ele está realizando uma "filosofia da consciência". Não se trata de uma intencionalidade. De um direcionar a. É um "algo" - algo que apela, algo que faz o Dasein apelar a si:

o apelo não é precisamente, nem nunca pode ser planejado, preparado e executado voluntariamente por nós mesmos. 'Algo' apela, contrariando a esperança e contrariando mesmo a vontade. Por outro lado, é indubitável que o apelo não provém de um outro que esteja comigo no mundo. $\mathrm{O}$ apelo provém de mim e, no entanto, de além de mim (HEIDEGGER, 2012b, pp. 755-757).

Seria injusto dizermos que não há aqui uma inspiração husserliana. Afinal, na gramática do seu professor poderíamos perguntar: o que levaria um sujeito a realizar uma suspensão de todos os juízos? O que o levaria a fazer uma redução fenomenológica e começar a duvidar de tudo? Há "algo" que o faz fazer algo. Esse "algo", essa "coisa", é um poder estranho do Dasein segundo Heidegger. Estranho no sentido mesmo em que Freud diz Unheimlich: aquilo que é o mais familiar e, ao mesmo tempo, 
desconhecido/estranho. Como não ressoar essa reflexão nestas palavras de Freud?: “(...) o inquietante [Unheimlich - que é também traduzido por estranho] é aquela espécie de coisa assustadora que remonta ao que é há muito conhecido, ao bastante familiar" (FREUD, 2010a, p. 331). Eis as palavras de Heidegger sobre a mesma questão: "ele é o Dasein em seu estranhamento [Unheimlichkeit], o originário dejectado no ser-no-mundo como fora-de-casa, o desnudo 'quê' no nada do mundo" (HEIDEGGER, 2012b, p. 759).

É nesse ponto que fica claro o que seria a angústia para Heidegger: esta defrontação com algo familiar (o poder-ser mais próprio) e estranho (poder, afinal, ser esse poder-ser mais próprio).

A consciência enquanto uma possibilidade do Dasein frente a um estranhamento. Eis a tese de Heidegger:

\begin{abstract}
o estranhamento [Unheimlichkeit] é o modo fundamental do ser-no-mundo, apesar de cotidianamente encoberto. O Dasein ele mesmo é que apela como consciência a partir do fundamento desse ser. O 'algo me chama' é um discurso assinalado do Dasein. O apelo repassado pelo estado-de-ânimo da angústia possibilita pela primeira vez que o Dasein se projete a si mesmo em seu poder-ser mais-próprio. $\mathrm{O}$ apelo da consciência existenciariamente entendido comprova pela primeira vez o que foi anteriormente afirmado: o estranhamento persegue o Dasein e ameaça a sua esquecida perda de si mesmo (HEIDEGGER, 2012b, p. 761).
\end{abstract}

Perdido num falatório, numa ambiguidade, numa curiosidade, o Dasein perde a si mesmo. Mas há sempre a possibilidade do apelo ser ouvido. Ser-para-a-morte - isso ressoa... Uma nulidade de si (um apagamento de si de forma completamente diferente de um apagamento de si na "multidão"): "no estranhamento o Dasein fica originariamente junto consigo mesmo. $\mathrm{O}$ estranhamento põe esse ente ante sua indissimulada nulidade, pertencente à possibilidade de seu poder-ser mais-próprio" (HEIDEGGER, 2012b, p. 785).

É como se o Dasein, por estar jogado/dejectado no mundo, tivesse que voltar a si mesmo (e, ao mesmo tempo, por uma questão estruturalmente ontológica, ser-junto-aos-outros) para poder ser si mesmo. Estando jogado aqui (no mundo), ele deve a si mesmo sua "propriedade" (ser o mais próprio possível, singular). A consciência entra neste ponto: "a consciência só apela se calando, isto é, o apelo provém da não-proferição do estranhamento e apela para que o Dasein retorne também calado ao silêncio de si-mesmo" (HEIDEGGER, 2012b, p. 811).

Estando num falatório, o Dasein é "culpado" de velar a si nessa falação (se perder no cotidiano). Teríamos uma espécie de "débito", uma vez que, neste destino, “(...) o Dasein é ele mesmo uma nulidade de si mesmo" (HEIDEGGER, 2012b, p. 781). Mas estar abandonado a si mesmo 
não é uma privação ou um defeito ou um déficit - é algo que faz parte do estranhamento do Dasein.

São estes momentos que levam alguns filósofos, como Jean-Paul Sartre, a lerem as páginas heideggerianas enquanto um existencialismo. É "quase natural" pensarmos isto ao lermos:

\begin{abstract}
o entender-o-apelo abre o próprio Dasein no estranhamento do seu isolamento. $\mathrm{O}$ estranhamento que se desvenda ao mesmo tempo no entender é genuinamente aberto pelo encontrar-se da angústia que lhe pertence. O factum da angústia-daconsciência confirma fenomenicamente que o Dasein, no entender-o-apelo, é conduzido ante o estranhamento de si mesmo. O querer-ter-consciência torna-se um ficar-pronto para a angústia (HEIDEGGER, 2012, p. 809).
\end{abstract}

Mas Heidegger não dá um "privilégio" à consciência. Seu suposto "privilégio" é uma das possibilidades do modo-de-ser do Dasein. A consciência - enquanto um modo de ser possível - não é o tema central da filosofia como aparece na fenomenologia de Husserl. Heidegger, desde o Ser e o Tempo (1927), propunha algo que ia noutra direção:

sobre o fundamento do modo-de-ser que é constituído pelo existenciário do projeto, o Dasein é constantemente 'mais' do que ele de fato é, se se quisesse e se pudesse tomar seu conteúdo-de-ser como o conteúdo de um subsistente. Mas ele nunca é mais do que é factualmente, porque o poder-ser pertence essencialmente à sua factualidade. Mas o Dasein como ser-possível não é também menos; isto é, o que ele em seu poder-ser ainda não é, ele o é existenciariamente. É só porque o ser do 'aí' recebe sua constituição pelo entender e pelo seu caráter-de-projeto, porque ele é aquilo em que se torna ou não se torna, pode ele entendendo a si mesmo dizer: 'tornate o que és!' (HIEDEGGER, 2012b, pp. 413-415).

que se é?

Como fazer isto? Esta é uma outra questão... É possível tornar-se o

\title{
Referências bibliográficas
}

HEIDEGGER, Martin. Logic - The question of truth. Translated by Thomas Sheehan. Indiana: Indiana University Press, 2010.

Os problemas fundamentais da fenomenologia. Tradução de Marco

Antônio Casanova. Petrópolis: Vozes, 2012a.

. Ser e Tempo (edição em alemão e português). Tradução de Fausto

Castilho. Campinas: Unicamp; Petrópolis: Rio de Janeiro, 2012b.

FREUD, Sigmund. O inquietante. In: História de uma neurose infantil; além do princípio do prazer e outros textos (1917-1920). Tradução de Paulo César de Souza. São Paulo: Companhia das Letras, 2010. 
GADAMER, Hans-Georg. Hermenêutica em retrospectiva. Tradução de Marco Antônio Casanova. Petrópolis: Vozes, 2012.

Verdade e Método - Traços fundamentais de uma hermenêutica filosófica. Tradução de Flávio Paulo Meurer. Petrópolis: Vozes, 1997.

GIACOIA JR., Oswaldo. Heidegger urgente - Introdução a um novo pensar. São Paulo: Três Estrelas, 2013.

RILKE, Rainer Maria. Cartas a um jovem poeta: a canção de amor e de morte do porta-estandarte Cristóvão Rilke. Tradução de Poulo Rónai e Cecília Meireles. São Paulo: Globo, 2003. 